\title{
The detection of experimental myocardial infarcts by photoseanning
}

\section{A preliminary report}

\author{
Edward A. Carr, Jr., M.D. \\ William H. Beierwaltes, M.D. \\ Mury Ellen Patno, Ph.D. \\ John D. Bartlett, Jr., B.S. \\ Audrey V. Wegst, M.S. \\ Ann Arbor, Mich.
}

$\mathrm{T}$ The heart shadow as visualized roentgenographically is the result of superimposition of several tissues, including the blood content of the heart. Other roentgenographic and radioisotopic techniques used to visualize the heart show only its cavities. The studies of Burch and his associates,,$^{1,2}$ which indicated rapid uptake of rubidium- 86 by the myocardium, suggested the possibility of demonstrating the myocardium by photoscanning after administration of this radioisotope. Our previous wor $\mathrm{k}^{3}$ confirmed the feasibility of demonstrating the myocardium of the beating heart of living dogs by this technique. Furthermore, in photoscintigrams of the excised hearts of dogs previously subjected to coronary artery ligation, the area of infarction was demonstrable as a "cold" area of relatively decreased uptake of rubidium-86 (Fig. 1).

The successful use of mercury-203labeled chlormerodrin (Neohydrin) in the demonstration of brain tumors by photoscanning ${ }^{4-6}$ suggested the possible use of this compound to demonstrate myocardial infarcts as "hot" areas of relatively in- creased concentration of radioisotope in photoscintigrams of the heart. The present communication describes experiments designed to explore this possibility.

\section{Methods}

Coronary artery ligations.* Ten mongrel dogs were anesthetized with sodium pentobarbital, given intravenously. While respiration was maintained by a pump connected to an intratracheal catheter, the heart was exposed through a left lateral thoracic incision, employing subperiosteal resection of a portion of one rib. The pericardium was opened and a ligature passed around the anterior descending branch of the left coronary artery just below the bifurcation. After a loose single knot had been tied in the ligature, the shaft of a No. 20 needle was placed in the loop parallel to the artery and the ligature drawn tight. This incomplete occlusion of the artery was allowed to persist for about 10 minutes. The needle was then withdrawn, the ligature tightened down on the artery to occlude it completely, and the knot completed. The incision was then

\footnotetext{
From thr Departments of Internal Medicine (Clinical Radioisotope Unit and Kresge Research Radioisotope Unit.), Pharmacology, Radiology, and Biostatistics, University of Michigan, Ann Arbor, Mich.

This study was supported by the Isotope Unit Research Fund and the Michigan Memorial Phoenix Project No. 220. Received for publication March 14, 1962.
}

*The helpful advice of Dr. Lloyd Beck is gratefully acknowledged. 


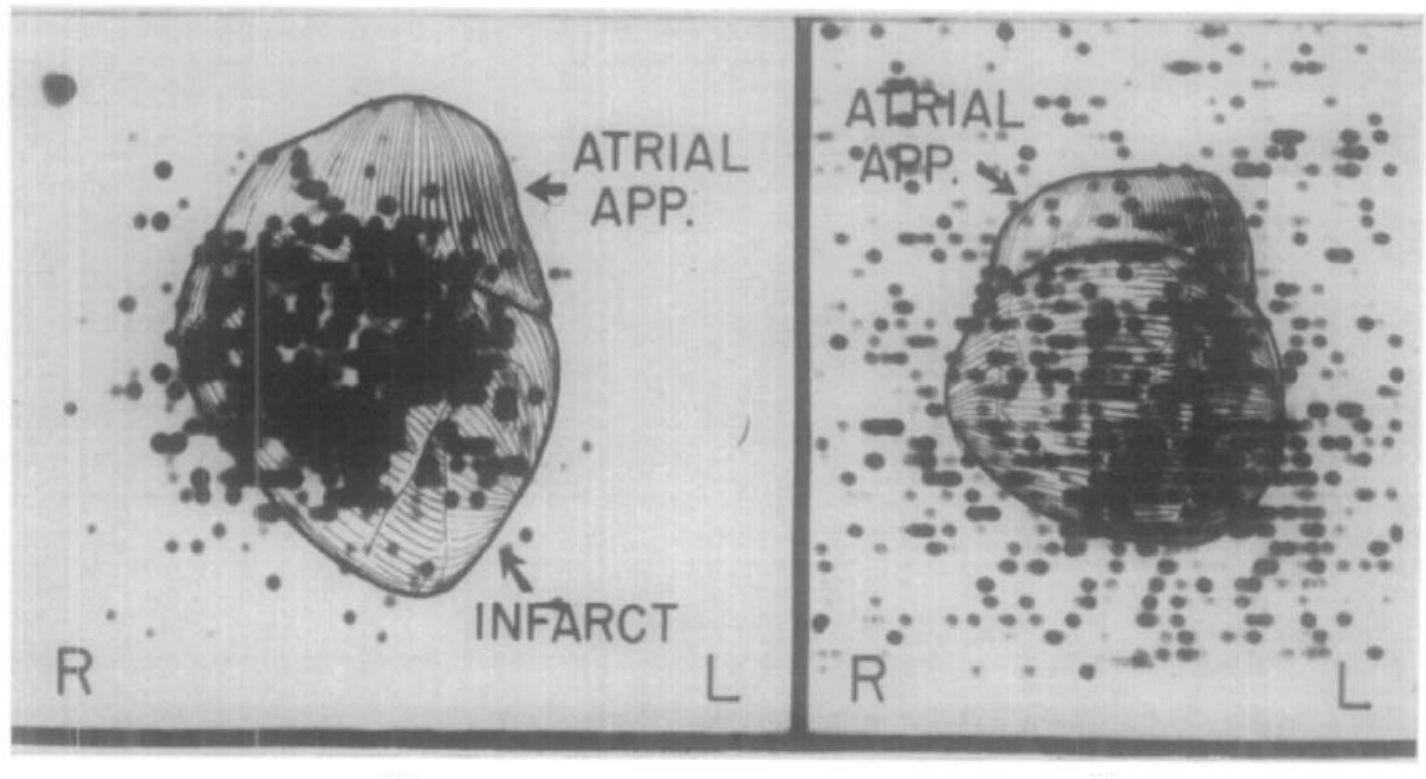

a.

Fig. 1. Photoscintigrams of isolated hearts of 2 dogs that had received $\mathrm{Rb}^{86} \mathrm{Cl}$. In this and all subsequent figures, all outlines drawn as heavy black lines on the photoscintigrams were obtained by direct projection (see text) Only the faint shading to indicate cardiac tissue has been added by the illustrator. $A$, Heart from a dog with a myocardial infarct in the indicated area, confirmed histologically. $B$, Heart from a control dog. The infarct is seen as a "cold" area. The lower concentration of $\mathrm{Rb}^{86}$ in this area was subsequently confirmed by direct counting of radioactivity in tissue samples.

closed in layers. Nine dogs, which ranged in weight from 7.0 to 12.2 kilograms, survived the operation 24 hours or more. The other dog is not considered further in this report.

Sham operations. As controls, 5 dogs, which ranged in weight from 7.6 to 12.4 kilograms, were subjected to operation in the same manner as the previous group, except that no ligature was placed around the coronary artery after the pericardium had been opened.

Scanning. One to 21 days after operation each $\operatorname{dog}$ received $700 \mu \mathrm{c}$ of $\mathrm{Hg}^{203}$-chlormerodrin* intravenously. Scanning began 40 minutes to 25 hours after administration of the labeled compound. In preparation for scanning, each dog was again anesthetized by intravenous injection of sodium pentobarbital and placed in the supine position on a table. The legs of the dog were extended and firmly tied. An area which extended from about $1 \mathrm{~cm}$. below the xiphoid to about $2 \mathrm{~cm}$. below the cephalic border of the manubrium

\footnotetext{
*Abbott Laboratories, Oak Ridge, Tenn.; F. R. Squibb and Sons, Cleveland, Ohio.
}

sterni, and which extended beyond the lateral thoracic walls on each side, was then scanned with a photoscanner* equipped with a 3 by 2 -inch crystal and a 19 -hole focusing collimator. The edge of the collimator was placed about $1 \mathrm{~cm}$. above the anterior chest wall at the level of the sternum. Scanning speed was usually 16 $\mathrm{cm}$. per minute. The contrast adjustment of the scanner was set at the " 15 " position, a setting designed for sharp contrast. Before every scan, the probe was repeatedly moved manually over the entire precordial area until the spot of greatest radioactivity was found. The voltage of the scanner was then adjusted to yield maximum blackness of the photoscintigram over this area.

At the conclusion of the scan, the animal was left in position and sacrificed by intraperitoneal injection of 10 to $20 \mathrm{ml}$. of a solution of sodium pentobarbital in isopropyl alcohol and propylene glycol. $\dagger$

\footnotetext{
*Picker Magnascanner, Picker X-Ray Corporation, White Plains, N. Y,

†"Lethal" solution, Haver-Lockhart Laboratories, Kansas City, Mo.
} 


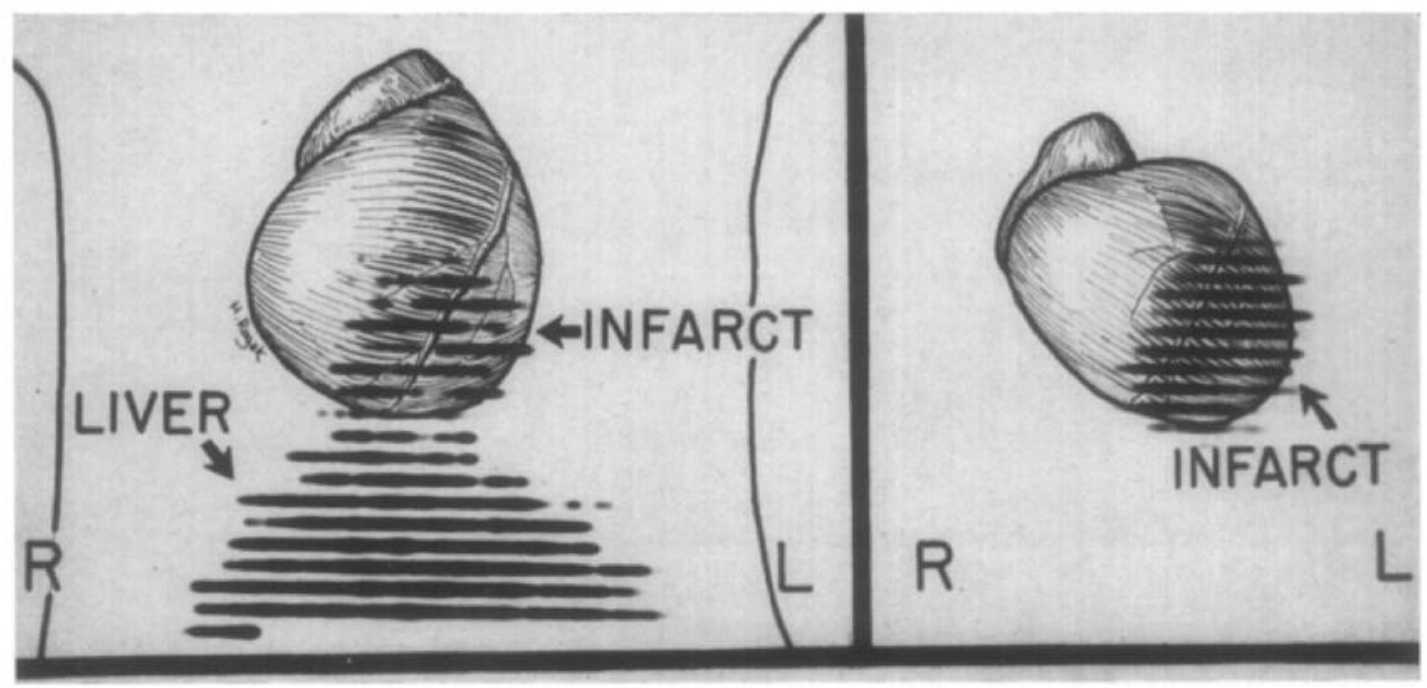

1.

$B$.

Fig. 2. Photoscintigrams of the heart of a $\operatorname{dog}$ (Dog 2, Table I) which had received $\mathrm{Hg}^{203}$-chlormerodrin after coronary artery ligation with myocardial infarction. In this and subsequent figures, $A$ shows the photoscintigram obtained in the living dog; the projections of heart, body wall, coronary artery, and atrioventricular sulcus were added after death. B shows the same heart, rescanned after removal from the dog. The "hot" area seen in the heart of the living dog and in the same isolated heart corresponds to the area of infarction, demonstrated histologically. The localization of $\mathrm{Hg}^{203}$ in this area was subsequently confirmed by direct counting of radioactivity in tissue samples.

With the aid of a narrow light beam attached to the collimator, the probe was centered over the xiphoid and over the cephalic tip of the sternum, and their precise positions were projected on the dot scan which had been obtained simultaneously with the photoscan.

The heart was then fixed in position by inserting several (usually 3) long, sharp steel needles through the anterior chest wall in such a way as to transfix the heart. The points of the needles were driven firmly into the posterior thoracic wall of the dog. Without any change in the position of the carcass or needles, the central portion of the anterior chest wall was dissected free and removed. After the pericardium had been reflected, the entire outline of the exposed heart and the position of the anterior descending branch of the left coronary artery were projected onto the dot scan. After development of the photoscan, it was superimposed on the dot scan, and the markings on the latter were transferred to the former.

The heart was then removed and carefully freed of all blood by repeated washings with isotonic saline solution. In most instances this was facilitated by an incision in each lateral margin of the heart, opening the cavities of the ventricles. After the heart had been washed free of blood, the incisions were closed by sutures, and the isolated heart was rescanned with appropriate readjustment of scanning factors and collimator distance.

Tissue studies. Samples (35 mg. to 2.8 $\mathrm{Gm}$.) of left ventricle, right ventricle, atrium, and various other tissues (Table 1 ) were taken, and their radioactivity was determined in a well-type scintillation counter. Samples of left ventricle regularly included some from the area supplied by the anterior descending branch of the left coronary artery and others from areas in the posterior wall of the left ventricle supplied by the nonligated circumflex branch. All samples of left ventricle were placed in formalin after counting and examined histologically by a member of the staff of the Department of Pathology* who was not informed of the results of scanning or tissue counting.

*The valuable services of Dr. Robert Schmidt and Dr. Robert Hendrix are gratefully acknowledged. 


\section{Results}

Photoscintigrams. The results in a dog with a frank infarct are shown in Fig. 2. In the living dog a "hot" area of increased concentration of isotope was seen in the area of left ventricle supplied by the ligated artery (Fig. 2,A). The scan of the excised heart, emptied of blood, confirmed the presence of this "hot" area (Fig. 2,B).

In the scan of a sham-operated animal (Fig. 3, $A$ and $B$ ), no such area of increased concentration of isotope appeared. Although further discussion of scanning technology is beyond the scope of this paper, it should be noted that the method used here to set the scanner voltage and contrast (see Methods) produces a scan in which the criterion of normality or abnormality is contrast, not film density itself. If the distribution of isotope throughout the ventricles is relatively even (normal state), the scan shows considerable density throughout but no area of contrast. If there is very heavy concentration in one area (abnormal state), the scan shows one area of heavy density and little density elsewhere.

One finding in some scans of control dogs had a superficial resemblance to an infarct. This finding was a spindle-shaped area of moderately increased density on the right side of the heart, extending from the diaphragm toward and sometimes beyond the base of the heart. Such an area was seen in 2 of 7 dogs scanned from $2 \frac{1}{4}$ to $3 \frac{1}{2}$ hours after injection of the isotope, and in 1 of the 3 dogs scanned at the 7 to $73 / 4$-hour interval, but not in any of the dogs scanned on the day after injection. It was completely absent from all scans of isolated hearts emptied of blood. This indicated conclusively that the "spindle" did not have its origin in the myocardium; superimposition of blood in the caval veins upon the blood of the heart probably accounted for the density. Its characteristic shape, position, and extent made it distinguishable from an infarct.

Areas of "ischemia" without frank infarction (see below) were also clearly detectable on scans (Fig. $4, A$ and $B$ ). Thus, scans of "ligated" dogs were clearly different from those of sham-operated control dogs; in the former the areas of interrupted blood supply appeared positive in the presence or absence of frank myocardial necrosis.

\section{Tissue studies}

LEFT VENTRICLE. Since all coronary artery ligations were performed on the anterior

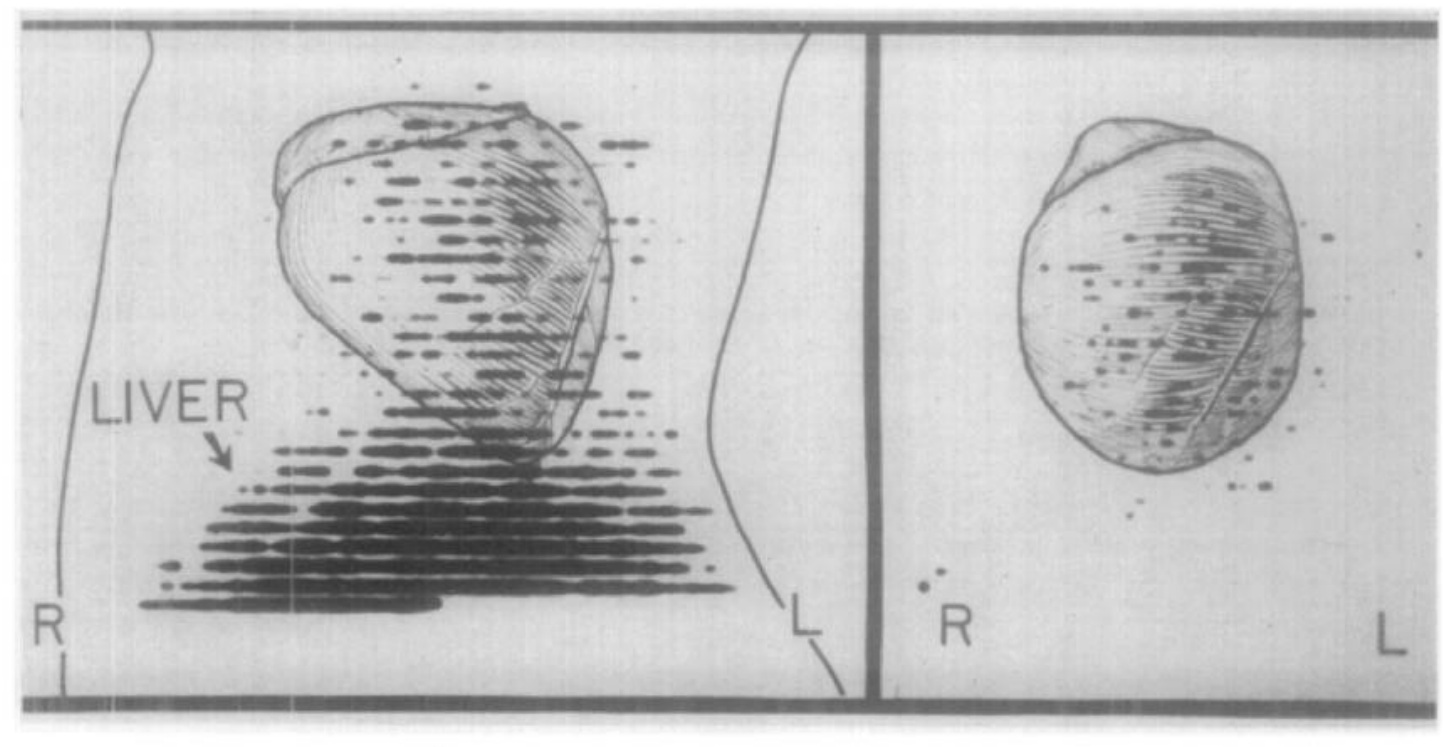

A.

B.

Fig. 3. Photoscintigrams of the heart of a $\operatorname{dog}$ (Dog 4, Table I) which had received $\mathrm{Hg}^{203}$-chlormerodrin after a sham operation. The heart shows a diffuse, even concentration of the isotope, with no well-localized "hot" area standing out in sharp contrast. The even distribution of $\mathrm{Hg}^{203}$ was subsequently confirmed by direct counting of radioactivity in tissue samples. 


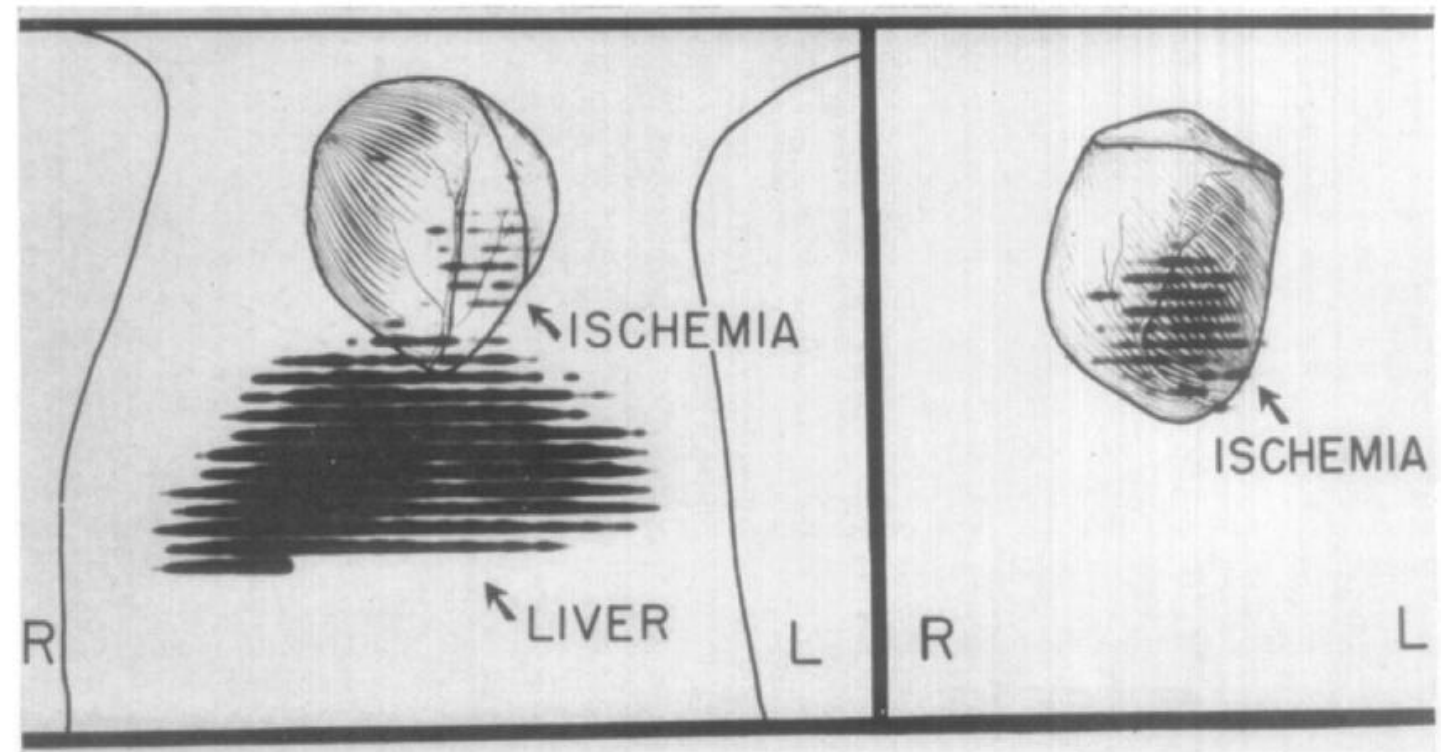

A.

bi.

Fig. 4. Photoscintigrams of the heart of a $\operatorname{dog}$ (Dog 1, Table I) which had received $\mathrm{Hg}^{203}$-chlormerodrin after coronary artery ligation without myocardial infarction. The "hot" area seen in the heart of the living dog and in the same isolated heart is restricted to the portion of left ventricle supplied by the ligated branch of the coronary artery. The localization of $\mathrm{Hg}^{203}$ in this area was subsequently confirmed by direct counting of radioactivity in tissue samples.

descending branch, all samples from the area supplied by this branch, i.e., the anterior ventricular wall, were classified as "anterior left ventricle, ligated" (see below) in Table I. Samples from the area supplied by the nonligated branch, i.e., the posterior ventricular wall, were classified as "posterior, left ventricle, normal" in Table I. Samples from the anterior and posterior ventricular walls of sham-operated dogs were classified as "anterior left ventricle, normal" and "posterior left ventricle, normal," respectively.

All samples classified as "normal" were found to be normal on histologic examination, except for occasional evidence of congestion, which was never marked or associated with any other definite histologic abnormality.

All samples which showed frank necrosis histologically came from the "anterior left ventricle, ligated" group. All other samples from the "anterior left ventricle, ligated" group, i.e., those that did not show actual necrosis, were arbitrarily classified as "ischemic." The justification for this subclassification will be discussed below. Some "ischemic" samples showed marked histologic abnormality, even though frank necrosis was absent, whereas others showed no clear histologic abnormality.

The data in Table I suggest little variation in the concentration of $\mathrm{Hg}^{203}$ within any individual normal left ventricle, with the unexplained exception of Dog 13. All samples of infarct showed a higher concentration of $\mathrm{Hg}^{203}$ than did all normal left ventricular samples from their respective hearts. Fifteen of the 16 "ischemic" samples showed a higher concentration of $\mathrm{Hg}^{203}$ than did all normal left ventricular samples from their respective hearts, even in Dog 13. Among "ischemic" samples no definite correlation was noted between the concentration of $\mathrm{Hg}^{203}$ and the degree of histologic change.

The variation in interval between injection of tracer and sacrifice of the animal made it desirable to compare relative as well as absolute concentrations of $\mathrm{Hg}^{203}$. In view of the clear inverse relation between the interval and the concentration of $\mathrm{Hg}^{203}$ in whole blood, the latter was used 
as the standard of comparison:

$$
\mathrm{R}=\frac{\frac{\Sigma}{\mathrm{n}}}{\mathrm{B}}
$$

where $\mathrm{R}=$ the relative concentration of $\mathrm{Hg}^{203}$ in any tissue of a given $\operatorname{dog} ; \chi=$ the concentration of $\mathrm{Hg}^{203}$ in a single sample, expressed as counts per minute per gram; $\mathrm{n}=$ the number of samples; $\mathrm{B}=$ the concentration of $\mathrm{Hg}^{203}$ in the same dog's blood, expressed as counts per minute per gram.

In Table II, the relative concentrations of $\mathrm{Hg}^{203}$ in left ventricle are compared. A significant difference $(0.0125<\mathrm{p}<0.025)$ was found by the "t" test between "anterior left ventricle, ligated" and "posterior left ventricle, normal" in the dogs subjected to ligation. No significant difference was found between "anterior left ventricle, normal" and "posterior left ventricle, normal" in the sham-operated dogs. Coronary artery ligation thus caused a significantly higher relative concentration of $\mathrm{Hg}^{203}$ in the area supplied by the ligated branch.

But the data in Table II show only a difference between normal areas and those supplied by a ligated branch. Since, as noted previously, both infarcts and "ischemic" areas had high concentrations of $\mathrm{Hg}^{203}$, the question of a difference between infarct and "ischemia" remains. In all 4 dogs (Dogs 6, 7, 8, and 13) in which samples in both abnormal subclasses were obtained, the relative concentration of $\mathrm{Hg}^{203}$ was found to be higher in infarcts than in "ischemic" samples. Moreover, since Dogs 1 and 2 were both sacrificed 21/4 hours after injection, comparison of the "ischemic" area in Dog 1 with the infarct in Dog 2 is germane. An analogous situation obtains with Dogs 10 and 9. In both instances the relative concentration of $\mathrm{Hg}^{203}$ was again found to be higher in infarcts than in "ischemic" samples. The data, therefore, suggest a somewhat higher relative concentration of $\mathrm{Hg}^{203}$ in infarcts than in "ischemic" areas.

Right ventricle. The concentration of $\mathrm{Hg}^{2{ }^{23}}$ did not differ significantly from that in normal left ventricle.

Atrium. The relative concentration of $\mathrm{Hg}^{203}$ was higher than that in posterior (normal) left ventricle in 10 of 13 dogs.
This difference is significant $(\mathrm{p}<0.05)$.

Other tissues. Absolute rather than relative concentrations are used here to facilitate comparison of concentrations of $\mathrm{Hg}^{203}$ among the normal tissues, including blood, of each individual dog. In each dog the concentration of $\mathrm{Hg}^{203}$ in liver was greater than that in any other normal tissue studied, including blood. The hepatic concentration was always higher than that in infarcts, except in Dogs 2 and 6. Next to liver, the concentration of $\mathrm{Hg}^{203}$ in lung was higher than that in other normal solid tissues, except for atrium and rib in one $\operatorname{dog}$ each. The concentration of $\mathrm{Hg}^{203}$ in lung was less than in blood in only 4 dogs, all of which were sacrificed before 8 hours. The pulmonary concentration of $\mathrm{Hg}^{203}$ was less than the concentration in infarcts in each dog, except Dog 9, but greater than that in "ischemic" samples in 5 of 7 dogs.

$R i b$ showed a concentration of $\mathrm{Hg}^{203}$ higher than that in normal left ventricle in 6 dogs, and a concentration higher than that in blood in 4 , including 3 sacrificed at 23 to 26 hours. The concentration of $\mathrm{Hg}^{203}$ in rib was always lower than the mean concentration in abnormal left ventricle of the same dog.

Fat and muscle had generally low concentrations of $\mathrm{Hg}^{203}$. In Dog 7, fat had a higher concentration of $\mathrm{Hg}^{203}$ than did "ischemic" left ventricle; otherwise, fat and muscle had a lower concentration of $\mathrm{Hg}^{203}$ than did abnormal left ventricle in each ligated dog.

\section{Discussion}

Photoscintigrams. These studies show that a myocardial infarct in the beating heart of a living animal can be demonstrated through the intact chest wall. The correctness of the identification of the infarcts in vivo has been confirmed in four ways: projection of the outline of the heart in situ on the scan obtained in vivo; redemonstration of positive areas on rescans of excised, emptied hearts; demonstration of increased concentration of $\mathrm{Hg}^{203}$ by direct counting of radioactivity in histologically confirmed lesions; and negative results in similarly studied controls subjected to a sham operation complete in every detail except for actual 


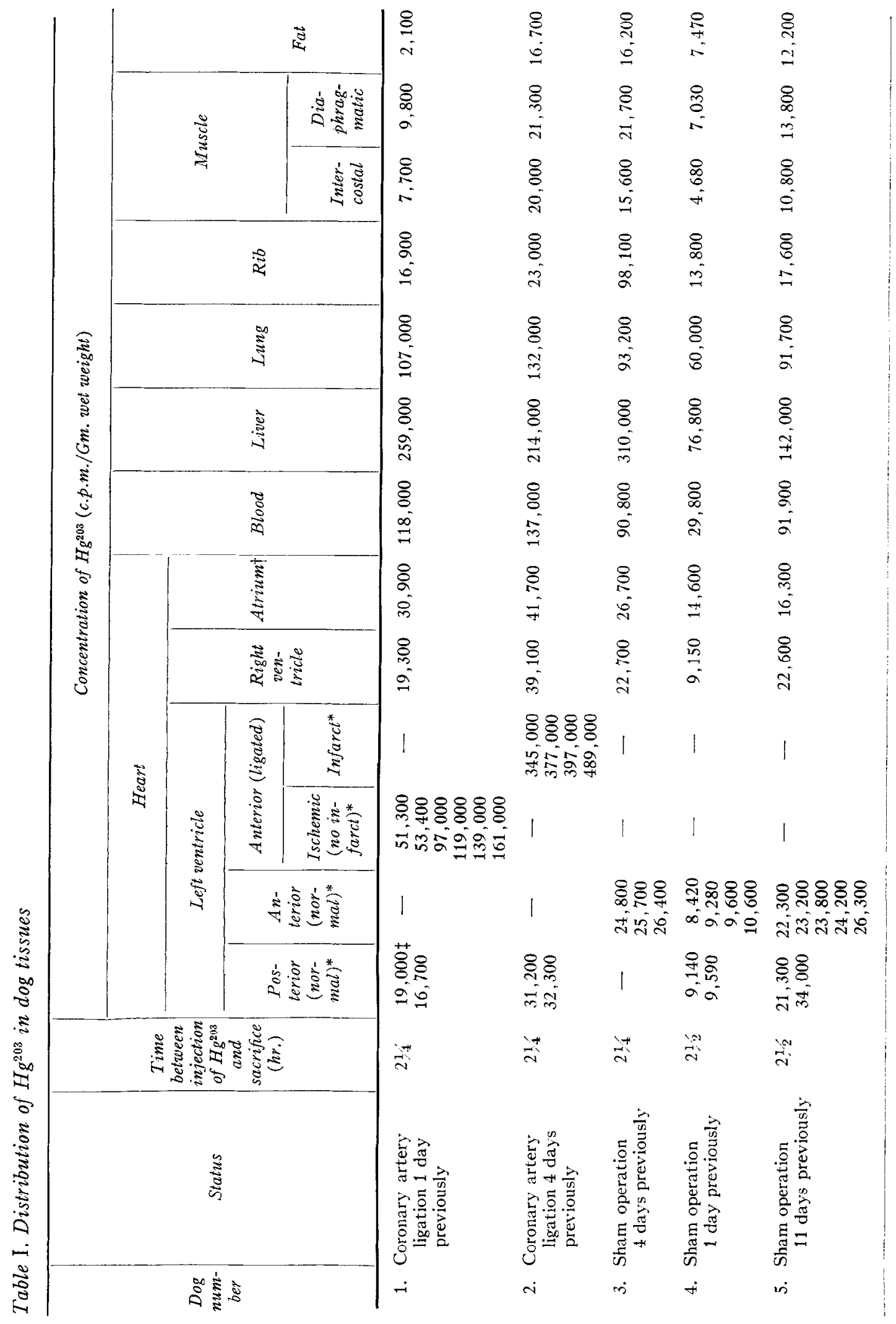




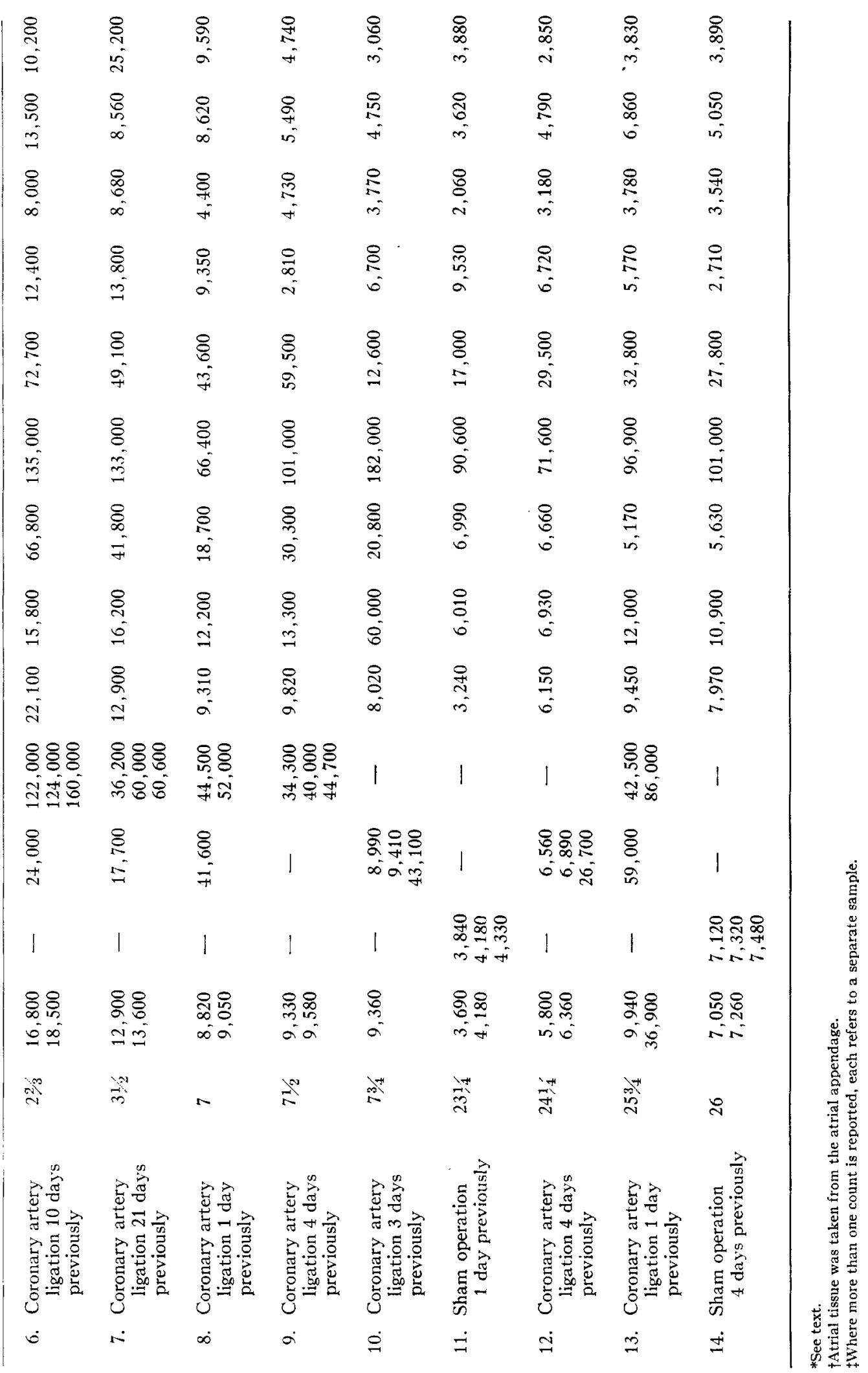


Table II. Relative concentration* of $\mathrm{Hg}^{203}$ in heart

\begin{tabular}{|c|c|c|c|c|c|c|}
\hline $\begin{array}{c}\text { Dog } \\
\text { number }\end{array}$ & Status & $\begin{array}{l}\text { Posterior left } \\
\text { ventricle } \\
\text { (normal) }\end{array}$ & $\begin{array}{c}\text { Anterior left } \\
\text { ventricle } \\
(\text { normal })\end{array}$ & $\begin{array}{c}\text { Anterior left } \\
\text { ventricle } \\
\text { (ligated) }\end{array}$ & $\begin{array}{l}\text { Diflerence betwieen } \\
\text { anterior and pos- } \\
\text { terior left ventricle }\end{array}$ & Atrium \\
\hline 1. & Ligated & 0.15 & - & 0.87 & 0.72 & 0.26 \\
\hline 2. & Ligated & 0.23 & -- & 2.93 & 2.70 & 0.30 \\
\hline 6. & Ligated & 0.26 & - . & 1.61 & 1.35 & 0.24 \\
\hline 7. & Ligated & 0.32 & -- & 1.04 & 0.72 & 0.39 \\
\hline 8. & Ligated & 0.48 & -- & 2.46 & 1.98 & 0.65 \\
\hline 9. & Ligated & 0.31 & - & 1.31 & 1.00 & 0.44 \\
\hline 10. & Ligated & 0.45 & $-\cdots$ & 0.99 & 0.54 & 2.88 \\
\hline 12. & Ligated & 0.91 & $\cdots$ & 2.01 & 1.10 & 1.04 \\
\hline \multirow[t]{2}{*}{13.} & Ligated & 4.53 & - & 11.90 & 7.37 & 2.32 \\
\hline & & & & \multicolumn{3}{|c|}{ Mean 1.94 } \\
\hline 3. & Sham operation & - & 0.28 & - & -- & 0.29 \\
\hline 4. & Sham operation & 0.31 & 0.32 & & 0.01 & 0.49 \\
\hline 5. & Sham operation & 0.26 & 0.30 & & 0.04 & 0.18 \\
\hline 11. & Sham operation & 0.56 & 0.59 & - & 0.03 & 0.86 \\
\hline \multirow[t]{2}{*}{14.} & Sham operation & 1.27 & 1.30 & - & 0.03 & 1.94 \\
\hline & & & & \multicolumn{3}{|c|}{ Mean $0.03 \$$} \\
\hline
\end{tabular}

*Relative concentration $=\frac{\frac{\Sigma \chi}{\mathrm{n}}}{\mathrm{B}}$, where $\chi=\left[\mathrm{Hg}^{203}\right]$ in a single sample, $\mathrm{n}=$ number of samples of a given dog's tissue, and $\left.\mathrm{B}=\mid \mathrm{Hg}^{2 / 3}\right]$ in blood.

†As explained in the text, this comprises both infarcts and "ischemic" areas.

$\ddagger$ This difference is significantly greater than zero ( $<<0.025$ ).

$\S$ This difference is not significantly greater than zero.

coronary ligation. The technique of projection of cardiac outlines and the results of excised heart scans and tissue counting indicate that the "hot" areas in the scans made in vivo did not come from noncardiac areas, e.g., the fundus of the stomach or the incision used in creating the infarct. Moreover, the incision was made in the lateral thoracic wall in such a way that any concentration of $\mathrm{Hg}^{203}$ in the incision would not be confused with the concentration in infarct in any event.

Among thoracic organs, rib, fat, and muscle did not have sufficient uptake of $\mathrm{Hg}^{203}$ to interfere significantly with the cardiac scans. In spite of the high concentration of $\mathrm{Hg}^{203}$ per unit weight of lung tissue, the lungs were not visualized in the photoscintigrams, because most of the volume of the intact lung is air. A more surprising result was our failure to visualize clearly the 21-day-old infarct, despite the high concentration of $\mathrm{Hg}^{203}$ in the lesion; the wall in the area of the infarct was, of course, thinner than uninvolved wall but was still about two thirds of normal thickness.

The high absolute concentrations of $\mathrm{Hg}^{203}$ in blood at the early intervals after injection did not per se prevent satisfactory scans, since the concentration of $\mathrm{Hg}^{203}$ in abnormal tissue was also very high at these early intervals; visualization of abnormal tissue depends inter alia upon the ratio of concentration of $\mathrm{Hg}^{203}$ in the tissue to the concentration in blood. But there was a definite trend toward higher relative concentrations of $\mathrm{Hg}^{203}$ at later times after injections of the tracer, i.c., the concentration of $\mathrm{Hg}^{203}$ in blood fell more rapidly than that in tissue. This suggests that scans made at 8 or 24 hours should show relatively less background radioactivity in blood than scans made during the first 8 hours after injection. As noted previously, this may have practical importance in 
one respect, i.e., the "spindle" artefact appeared in some scans made at intervals up to 8 hours after injection but not in any made at later times. Nevertheless, except for this one suggested difference, our photoscintigrams to date do not clearly indicate that those made at 2 hours are generally inferior for the detection of infarcts or "ischemia" to those made at 24 hours. It is possible that the trend toward higher ratios of concentrations of $\mathrm{Hg}^{203}$ in abnormal left ventricle to concentrations of $\mathrm{Hg}^{203}$ in normal left ventricle at the early intervals offered an advantage to early scans, offsetting the disadvantage just discussed. Because the number of dogs scanned at each interval was not large, judgment as to the best time for scanning must be reserved.

Under optimal conditions of scanning, what percentage of ligated dogs would yield diagnostic scans? Since we do not claim to have established optimal conditions at present, this question cannot be answered with any certainty. However, previous experiences with scans of other organs, using the same type of photoscanner employed in the present study, suggest that the minimal detectable difference between two concentrations of radioactivity, under optimal conditions, is roughly 15 per cent. Seven of the 9 dogs ligated had minimum concentrations of $\mathrm{Hg}^{203}$ in infarcts or "ischemic" areas that were $\geq 15$ per cent above the maximum concentrations in normal left ventricle.

Tissue studies. The relation of concentrations of $\mathrm{Hg}^{203}$ in tissue to the results seen in the photoscintigrams has becn discussed above.

A possible relationship between the age of the infarct and the concentration of $\mathrm{Hg}^{203}$ was sought by making comparisons among dogs sacrificed at the same interval after injection of the tracer. No such relation was apparent. A separate series of experiments designed to clarify this single point inighı, of course, demonstrate such a difference, especially if infarcts more than 21 days old were studied.

Borghgraef and $\mathrm{Pitts}^{7}$ and Kessler, Lozano and Pitts ${ }^{8}$ reported data on several normal dogs sacrificed 2 to 3 hours after injection of $\mathrm{Hg}^{203}$-chlormerodrin. The mean ratios of concentration of $\mathrm{Hg}^{203}$ in tissue to concentration of $\mathrm{Hg}^{203}$ in whole blood, in normal heart, liver, lung, and muscle of Dogs 1-7 in the present study, agree very closely with the mean ratios, concentration of $\mathrm{Hg}^{203}$ in tissue to concentration of $\mathrm{Hg}^{203}$ in plasma, for these same tissues, respectively, calculated from the combined data of these two other reports.

The reason for the localization of $\mathrm{Hg}^{203}$ in infarcts is uncertain and deserves further study. Dogs in which only the coronary artery was ligated (the patency of the accompanying veins was carefully preserved and later confirmed at autopsy) showed concentrations of $\mathrm{Hg}^{203}$ in their infarcts as high as those in dogs in which both artery and accompanying venous branches were ligated. It may seem surprising at first that an infarct produces a "hot" area with $\mathrm{Hg}^{203}$-chlormerodrin. One might expect an area of diminished blood supply to be "cold." But it must be stressed that coronary occlusion does not result in total obliteration of all blood supply to the distal area, else all coronary occlusions would invariably lead to irreparable necrosis. If then, the existence of any influx of tracer into the area of infarction is accepted, the concentration of tracer will depend not simply on the rate of entry but on the relation between the rates of entry and exit. Changes in vascular permeability and changes in tissue binding of $\mathrm{Hg}^{20}$ ? are two possible factors which influence retention of the tracer. Nordenström's arteriographic demonstration of increase in collaterals around an area of previous myocardial infarction may also be significant in this regard. "The relationship between the uptake of $\mathrm{Hg}^{203}$ in myocardial infarcts and its uptake by certain brain tumors is at present unknown.

The fact that renal infarcts appear as "cold" areas with $\mathrm{Hg}^{203}$-chlormerodrin, whereas myocardial infarcts are "hot," should cause no surprise, since the extremely high concentration of $\mathrm{Hg}^{203}$-chlormerodrin by normal kidney makes it a special case. A somewhat analogous situation has long been known to exist with regard to I $^{131}$ uptake by thyroid cancer, which usually appears as a "cold" area in comparison with the normal thyroid gland, but often appears "hot" after all normal thyroid tissue has been removed 
and the cancer is then being compared with other, normal neck tissues which have very low uptakes of iodine.*

The high concentration of $\mathrm{Hg}^{203}$ in areas of "ischemia" without frank necrosis is a finding of particular interest. Since postmortem examinations showed that the coronary ligature had held in every dog, it appeared reasonable to classify tissue distal to the ligature as abnormal in every instance, even in the absence of demonstrable infarction. The finding of a high concentration of $\mathrm{Hg}^{203}$ in 15 of 16 such noninfarcted samples distal to ligation is further validation that the areas were indeed abnormal, and even suggests that in certain dogs the tracer studies were a more sensitive index of damage than histologic findings.

Possible clinical applicability. Photoscanning after administration of $\mathrm{Hg}^{203}$ chlormerodrin is now under study for the diagnosis of human myocardial infarctions. There is no a priori reason why the technique developed in $\operatorname{dogs}$ should not be applicable to man. However, the highest dose of $\mathrm{Hg}^{203}$ in common clinical use now is $700 \mu \mathrm{c}$ (for the visualization of brain tumors). If one wishes to use a dose no higher than this for the visualization of myocardial infarcts in man, then the relative dose (microcuries per kilogram) in man will, of course, be considerably lower than that employed in dogs in the present study. It is possible, therefore, that the diagnosis of myocardial infarction in man after $700 \mu \mathrm{c}$ of $\mathrm{Hg}^{203}$ chlormerodrin may have to await improvement in the sensitivity of our instruments. Because photoscanners have been available for only a short period of time, expectation of such improvement does not seem visionary.

If successful, the usefulness of such a technique in clinical medicine would presumably be very high. Four possible special uses might be: diagnosis in patients with doubtful history or electrocardiogram (including patients with severe ischemia but no infarct); accurate localization of infarcts by direct visualization; direct demonstration of the progress of extension

*This analogy is, of course, only partly valid, since changes in secretion of TSH after thyroidectomy may affect the uptake by thyroid cancer. of an infarct; and recognition of impending infarction through localization of the tracer in areas of severe ischemia. Two important points of safety have already been established: the high specific activity of $\mathrm{Hg}^{203}$-chlormerodrin preparations already commercially available allows one to limit the dose of stable mercury to negligible amounts; and the mechanical arrangement of the scamner makes it entirely feasible to scan a patient without moving him from his bed. Therefore, although the transition from dog to man will not necessarily be either simple or inmediate, we are encouraged to report that a technique of diagnosis of myocardial infarction in dogs by photoscanning is now available, and that the method suggests, at least in principle, considerable usefulness and safety if it can be adapted to man.

\section{REFERENCES}

1. Burch, G. E., Threefoot, S. A., and Ray, C. 'T.: The rate of disappearance of $\mathrm{Rb}^{86}$ from the plasma, the biologic decay rates of $R b^{86}$, and the applicability of $\mathbf{R b}^{\mathbf{8 6}}$ as a tracer of potassium in man with and without chronic congestive failure, J. Lab. \& Clin. Med. 45:371, 1955.

2. Love, W. I)., Romney, R. B., and Burch, G. E.: A comparison of the distribution of potassium and exchangeable rubidium in the organs of the dog, using rubidiun-86, Circulation Res. 2:112, 1954 .

3. Carr, E. A., Jr., Beierwaltes, W. H., Wegst, A. V., and Bartlett, J. D., Jr.: Myocardial scanning with rubidium-86, J. Nucl. Med. $3: 76,1962$.

4. Blau, M., and Bender, M. A.: Radiomercury $\left(\mathrm{Hg}^{203}\right)$-labeled Neohydrin: a new agent for brain tumor localization, J. Nucl. Med. (special convention issue), p. 35, 1959.

5. Blau, M., and Bender, M. A.: Clinical evaluation of $\mathrm{Hg}^{203}$ Neohydrin and $\mathrm{I}^{131}$ albumin in brain tumor localization, J. Nucl. Med. 2:106, 1960.

6. Brinkman, C. A., Wegst, A. V., Haynie, 'T. P., and Nasjleti, C. E.: Localization of intracranial tumors utilizing $\mathrm{Hg}^{203}$-labeled $\mathrm{NeO}$ hydrin and the photoscanner, Univ. Michigall M. Bull. $27: 221,1961$.

7. Borghgraef, R. R. M., and Pitts, R. F.: 'The distribution of chlormerodrin (Neohydrin) in tissues of rat and $\operatorname{dog}$, J. Clin. Invest. 35:31, 1956.

8. Kessler, R. H., Lozano, R., and Pitts, R. F.: Studies on structure diuretic artivity relationships of organic compounds of mercury, J. Clin. Invest. $36: 656,1957$.

9. Nordenström, B., Ovenfors, C. O., and Törnell, G.: Myocardiography and demonstration of the cardiac veins in coronary angiography, Acta radiol. 57:11, 1962. 